\title{
Characteristics of three wheeler drivers, and driver factors associated with road traffic accidents of three wheelers registered in the urban council Panadura HMRC Sampath ${ }^{1}$, P Fonseka ${ }^{2}$
}

\section{Abstract \\ Introduction}

The study was carried out to describe the characteristics of three wheeler drivers and to determine the associated driver factors for the road traffic accidents involving three wheelers registered in the Urban Council, Panadura.

\section{Methodology}

A descriptive cross sectional study was carried out in the Urban Council (UC) area of Panadura. A total of 338 eligible three wheeler (TW) drivers were studied using a pretested interviewer administered questionnaire.

\section{Results}

The mean age of the three wheeler drivers was 33.3 (SD \pm 8 ) years. Fifty two percent $(n=175)$ had studied up to grades 6 to 10 and $42.3 \%(n=143)$ have sat for the G.C.E. (O/L) Examination. Their median monthly income was Rs.18000 (IQR 13000, 20000). 66\% $(n=223)$ were alcohol users, 53.6\% $(n=181)$ were smokers and 5.6\%( $n=19)$ were illicit drug users.

There were 49 (14.5\%) road traffic accidents (RTAs) involving TW drivers during the period of 6 months prior to the research. The occurrence of RTAs was significantly higher among the drivers who drive rented TWs (OR=2.48; 95\% CI: 1.32 - 4.66), who have the habit of driving after having alcohol $(\mathrm{OR}=2.06$; 95\% $\mathrm{CI}: 1.11$ - 3.79) and smoke while driving ( $\mathrm{OR}=2.27$; 95\% CI: 1.23 - 4.19) compared to drivers who drive their own TWs, who never drink and drive and who never smoke while driving respectively.

\section{Conclusions}

Alcohol use and smoking were common among TW drivers. RTAs are more common among drivers who drive rented TWs, who have the habit of drinking and driving and smoking while driving.

\section{Key words}

Three Wheeler, Road traffic accidents, Driver

\section{Introduction}

Inventions in the land transportation have contributed to the process of civilization and to modern developments to a great deal. The evolution in the motorized transportation not only affects the society positively but it has also generated numerous dire consequences. Road traffic accidents (RTA), environmental pollution, undesirable health effects are the foremost issues.

Considering the health impact and economical burden of the RTAs, the theme of the World Health Day of 2004 had been dedicated for "Road Safety" which aimed at promoting action to prevent road injuries.

1. MD Trainee in Community Medicine, Post Graduate Institute of Medicine, University of Colombo

2. Visiting Professor of Community Medicine, University of Sri Jayawardenepura 
RTA is defined in the world report on road traffic injury prevention as a collision involving at least one vehicle in motion on a public or private road that results in at least one person being injured or killed(1). In Sri Lankan context, RTA has been defined by Traffic Police Headquarters as a collision of a vehicle with a person, property or with another vehicle on a public road (2). The TW is a small vehicle having three wheels, which is an all-terrain motor vehicle (3). In Sri Lanka TWs play a major role in public transportation. Features such as, availability, convenience, speed in traffic jams, and, road maneuverability may be some of the reasons why they have become one of the popular methods of transport. Therefore, TWs are widely used in urban and suburbs areas as well as in very remote areas of the country. In 1979, the Department of Motor Traffic commenced registration of TWs as a separate vehicle category. By the year 2007 TWs became the second commonest vehicle to be registered in the country (4).

Therefore, TWs is a major contributor to the vehicle fleet on the roads and thereby to the problem of the RTAs in the country. According to the information from the Traffic Police Headquarters TWs were responsible for $13 \%$ of total reported RTAs in 2007. This trend had been almost the same for years 2005 and 2006. It is shown that the TWs are the third commonest vehicle to be responsible for accidents (5). The accidents reported to police may only represent the tip of the iceberg where unreported fraction may be much higher than the reported ones. According to Dharmarathne (2001), the passengers of public transport buses and TWs are the second commonest road users to be injured in RTAs 6).
Epidemiological triad in RTA includes human, vehicle and the environment, of which human factor is the major contributor (7). Although we need to understand all three factors to recommend preventive and control measures, human factor need to be more emphasised.

Therefore, the objective of the study was to describe the characteristics of TW drivers and to determine the associated driver factors in accidents involving three wheelers.

\section{Methods}

A cross sectional descriptive study was conducted in UC area Panadura. The drivers of the TWs registered in UC Panadura for passenger hiring purposes were taken as the study population. Only the TW drivers who were driving the same TWs for the previous six months period and who were based on the assigned respective TW stations were included in the study. All the drivers who were eligible and willing were recruited for the study.

The study instrument was an interviewer administered questionnaire, which included four main sections namely demographic and socio-economic information of TW drivers, their habits and behaviors, personal history of driving of TWs and information on the current driving pattern.

In the first section, basic demographic and social information of the driver including age, sex, ethnicity, religion, marital status, total monthly family income and level of education were collected. 
The second section was designed to inquire about the habits and behaviors of the TW driver which would have an impact on driving and vulnerability for accidents. These included usage of alcohol, smoking, drug abuse and engaging in physical exercises and spiritual activities.

Daily vigorous physical activity at least for 30 minutes continuously was considered as having 'adequate' physical exercise. This included aerobic exercises, gardening and team games. Spiritual activities included were activities such as observing "Pansil", praying or meditating at home and attending to religious activities at religious places.

The third section questions were set to gather information about the TW driver's eligibility in driving, availability of a valid driving license, the experience in driving, the details of the driving learning process and information about the of RTAs they have experienced while driving the TWs during the past six month period. The final section of the questionnaire inquired about the ownership of the TW, and status of the revenue license and the insurance policy, working hours, actions that would have an impact on the vulnerability for accidents including driving under the influence of alcohol, smoking and usage of mobile phone while driving.

In this study the age of the driver, educational level of the driver, experience in driving TWs, ownership of the TW, daily working hours, driving under the influence of alcohol and distractions to the driver such as using mobile phones while driving and smoking while driving were considered as the driver factors for occurrence of RTAs.
Two well trained data collectors were recruited to gather information. The list of registered TWs and their relevant running stations were obtained from the Special Commissioner of the UC Panadura. The list was verified with the office bearers of the TW Society in the station. Each TW driver was met personally and information was gathered at his convenience. In order to minimize the disturbances to their routine activities, data collection started from the middle of the queue, while the drivers were waiting for their turn of hire.

Data entry and analysis was done using Statistical Package for Social Sciences (SPSS) 16.0 version by using a personal computer. Odds ratios and $95 \%$ confident intervals were calculated. Chi squared test was used and p value less than 0.05 was considered as significant.

\section{Results}

There were $402 \mathrm{TWs}$ registered in UC Panadura for passenger hiring purpose and they were based in 32 TW stations. Out of all registered TWs 352 were eligible for the study. The total number of drivers who had responded to the study was 338 . The response rate among the drivers was $96 \%$.

\section{Demographic and Socio Economic Characteristics.}

The total study populations were males and Sinhalese. The mean age of the TW drivers was $33.3(\mathrm{SD} \pm 8)$ years.

The median monthly income of the TW drivers was Sri Lankan Rupees (SLR) 18000 (IQR 13000, 20000) Table 1 presents the demographic and socioeconomic information of the study population. 


\section{Table 1}

Frequency distribution of demographic and socio economic characteristics. of the drivers of three wheelers

\begin{tabular}{|c|c|c|}
\hline Characteristics & Frequency $(n=338)$ & Percentage \\
\hline \multicolumn{3}{|l|}{ Age } \\
\hline$<25 y$ & 56 & 16.6 \\
\hline $26-35 y$ & 148 & 43.8 \\
\hline $36-45 y$ & 108 & 31.9 \\
\hline$>46 y$ & 26 & 7.7 \\
\hline \multicolumn{3}{|l|}{ Religion } \\
\hline Buddhist & 311 & 92.0 \\
\hline Roman Catholic & 27 & 8.0 \\
\hline \multicolumn{3}{|l|}{ Marital Status } \\
\hline Never married & 79 & 23.4 \\
\hline Married & 259 & 76.6 \\
\hline \multicolumn{3}{|l|}{ Level of education } \\
\hline Grade 1 to 5 & 10 & 3.0 \\
\hline Grade 6 to 10 & 175 & 51.7 \\
\hline Sat for G C E $(\mathrm{O} / \mathrm{L})$ & 143 & 42.3 \\
\hline Sat for G C E (A/L) & 10 & 3.0 \\
\hline \multicolumn{3}{|c|}{ Monthly income (SLR) } \\
\hline$<10000$ & 51 & 15.1 \\
\hline $10001-20000$ & 197 & 58.3 \\
\hline$>20001$ & 90 & 26.6 \\
\hline
\end{tabular}

Habits and Behaviors of the TW Drivers

As indicate in Table 2 alcohol usage and smoking were $66 \%(\mathrm{n}=223)$ and $53.6 \%$ $(n=181)$ respectively. Only $5.6 \%(n=19)$ reported taking illicit drugs. The frequency distribution of pattern of physical exercising and engaging in spiritual activities are presented in Table 3. The percentage of drivers who perform adequate physical exercises was only $36.4 \%(n=123)$.
Personal history of driving of three wheelers

In the study population $99.4 \% \quad(n=336)$ of the drivers had a valid driving license to drive TWs belonging to either class A or E driving license. 
Table 2

Frequency distribution of substance use among the drivers TWs

\begin{tabular}{|c|c|c|}
\hline Characteristic & Frequency $(n=338)$ & Percentage \\
\hline \multicolumn{3}{|l|}{ Taking alcohol } \\
\hline Yes & 223 & 66.0 \\
\hline No & 115 & 34.0 \\
\hline \multicolumn{3}{|c|}{$\begin{array}{l}\text { Frequency of taking } \\
\text { alcohol }\end{array}$} \\
\hline Daily & 12 & 5.4 \\
\hline Once a week & 127 & 56.9 \\
\hline Occasionally & 84 & 37.7 \\
\hline \multicolumn{3}{|l|}{ Smoking } \\
\hline Yes & 181 & 53.6 \\
\hline No & 157 & 46.4 \\
\hline \multicolumn{3}{|c|}{$\begin{array}{l}\text { Average no of cigarettes } \\
\text { per day }\end{array}$} \\
\hline$<5$ & 103 & 56.9 \\
\hline $6-10$ & 74 & 40.9 \\
\hline$>11$ & 4 & 2.2 \\
\hline \multicolumn{3}{|c|}{ Usage of illicit drugs } \\
\hline Yes & 19 & 5.6 \\
\hline No & 319 & 94.4 \\
\hline \multicolumn{3}{|l|}{ Type of drug } \\
\hline Heroin & 1 & 5.3 \\
\hline Cannabis & 18 & 94.7 \\
\hline \multicolumn{3}{|c|}{$\begin{array}{l}\text { Frequency of usage of } \\
\text { drugs }\end{array}$} \\
\hline Daily & 1 & 5.3 \\
\hline Once a week & 11 & 57.9 \\
\hline Occasionally & 7 & 36.8 \\
\hline
\end{tabular}


Table 3

Frequency distribution of the physical exercise and spiritual activity among the drivers of TWs

\begin{tabular}{lcc}
\hline Characteristic & Frequency & Percentage \\
\hline Physical exercise & 123 & 36.4 \\
$\quad$ Yes & 215 & 63.6 \\
No & & \\
Frequency of physical exercises & 4 & 3.3 \\
Daily & 101 & 82.1 \\
Once a week & 18 & 14.6 \\
Occasionally & & \\
Spiritual activity & 327 & 96.7 \\
Yes & 11 & 3.3 \\
No & & \\
\hline
\end{tabular}

Although driving license class categories $\mathrm{A}, \mathrm{A} 1, \mathrm{~B}, \mathrm{~B} 1, \mathrm{E}, \mathrm{F}$ are valid to drive TWs the study population had only class A or E. Table 4 presents the information on the method and time spent on learning to drive the TW. Majority of TW drivers $(92.9 \% \mathrm{n}=314)$ had learnt to drive the TWs themselves and $87.2 \%$ $(n=295)$ of the population had spent $\leq 3$ days to learn to drive.

\section{Association of RTA with selected driver factors}

There were 49 (14.5\%) RTAs among the study population during the past six months period. The type of the accident is presented in Table 5. Out of the driver factors studied occurrence of RTAs was significantly higher among drivers who drive rented TWs $(\mathrm{p}=.004)$, who have the habit of drink and drive $(\mathrm{p}=0.02)$, and smoke while driving $(\mathrm{p}=0.007)$. None of the other variables given in Table 6 were significantly associated with the occurrence of RTA.

\section{Discussion}

This study found that a majority of the TW drivers were middle aged males. This finding is compatible with findings of the study done on TW drivers in Sri Lanka by Somasundaraswarans and Tay in 2005 (8) All drivers in the study population has had at least primary education. The prevalence of usage of alcohol among the divers was $66 \%$ and $41 \%$ took alcohol at least once a week. 


\section{Table 4}

Frequency distribution the method of learning to drive TWs, and the time spent on learning TWs, among the study population.

\begin{tabular}{lcc}
\hline Characteristic & Frequency & Percentage \\
\hline Method of Learning & & \\
From a registered learners & 7 & 2.1 \\
From another 3W driver & 17 & 5.0 \\
The driver himself & 314 & 92.9 \\
& & \\
Time spent on learning in days & & \\
1 & 141 & 41.7 \\
2 & 107 & 31.7 \\
3 & 47 & 13.9 \\
$\geq 4$ & 43 & 12.7 \\
\hline
\end{tabular}

Table 5

Frequency distribution of RTAs involving TWs by the type of the accident.

\begin{tabular}{ccc}
\hline Type of the accident & Frequency & Percentage \\
\hline TW + Pedal cycle & 10 & 20.4 \\
TW + Motor cycle & 8 & 16.3 \\
TW + TW & 5 & 10.2 \\
TW + Other Vehicle & 15 & 30.6 \\
TW + Pedestrian & 5 & 10.2 \\
TW + Passenger & 3 & 6.1 \\
TW + Animal & 1 & 2.1 \\
Other & 2 & 4.1 \\
Total & $\mathbf{4 9}$ & $\mathbf{1 0 0 . 0}$ \\
\hline
\end{tabular}


Table 6

Odds ratios for RTA involving TWs by selected driver factors

\begin{tabular}{|c|c|c|c|c|c|c|c|}
\hline \multirow{3}{*}{ Driver Factors } & \multicolumn{3}{|c|}{ RTA } & \multirow{3}{*}{ OR } & \multirow{3}{*}{$95 \% C I$} & \multirow{3}{*}{$\begin{array}{c}X^{2} \\
(d f=1)\end{array}$} & \multirow{3}{*}{$\begin{array}{c}P \\
\text { Value }\end{array}$} \\
\hline & \multicolumn{2}{|c|}{ Yes } & No & & & & \\
\hline & $n=49$ & $(\%)$ & $\mathrm{n}=289$ & & & & \\
\hline \multicolumn{8}{|l|}{ Driver age in years } \\
\hline$\leq 35$ & 30 & $(61.2)$ & 174 (60.2) & \multirow[b]{2}{*}{1.04} & \multirow[b]{2}{*}{$0.59-1.94$} & \multirow[b]{2}{*}{0.02} & \multirow[b]{2}{*}{0.89} \\
\hline$>35$ & & $(38.8)$ & $115(39.8)$ & & & & \\
\hline \multicolumn{8}{|l|}{ Level of education } \\
\hline Below GCE (O/L) & 28 & $(57.1)$ & $157(54.3)$ & \multirow[b]{2}{*}{1.12} & \multirow[b]{2}{*}{$0.61-2.06$} & \multirow[b]{2}{*}{0.14} & \multirow[b]{2}{*}{0.71} \\
\hline GCE $(\mathrm{O} / \mathrm{L}) \&$ above & & $(429)$ & $132(457)$ & & & & \\
\hline \multicolumn{8}{|c|}{ Driving experience in years } \\
\hline$\leq 10$ & 37 & (75.5) & $194(67.1)$ & \multirow{2}{*}{1.51} & \multirow{2}{*}{$0.75-3.03$} & \multirow{2}{*}{1.36} & \multirow{2}{*}{0.24} \\
\hline$>10$ & 12 & (24.5) & $95 \quad(32.9)$ & & & & \\
\hline
\end{tabular}

Ownership of the TW

\begin{tabular}{|c|c|c|c|c|c|c|c|}
\hline Rented & $21 \quad(42.9)$ & 67 & (23.2) & & & & \\
\hline Owned by driver & $28 \quad(57.1)$ & 222 & & 2.48 & $1.32-4.66$ & 8.42 & 0.004 \\
\hline
\end{tabular}

Working hours per day

$\begin{array}{lllllllll}\geq 12 & 34 & (69.4) & 157 & (54.3) & & & & \\ <12 & 15 & (30.6) & 132 & (45.7) & & & & \\ & & & & & & & & \end{array}$

Drink and drive

Sometimes

$24 \quad(49)$

$92(31.8)$

Never

$25(51)$

$197 \quad(68.2)$

$2.06 \quad 1.11-3.79 \quad 5.46 \quad 0.02$

Smoke while driving

Sometimes

$26 \quad(53.1)$

$96 \quad(33.2)$

Never

$23(46.9)$

$193 \quad(66.8)$

$\begin{array}{llll}2.27 & 1.23-4.19 & 7.15 & 0.007\end{array}$

Using mobile phones while driving

Sometimes

$28 \quad(57.1)$

$127 \quad(43.9)$

Never

$21(42.9)$

$162(56.1)$

$\begin{array}{llll}1.7 & 0.92-3.13 & 2.94 & 0.09\end{array}$ 
This prevalence of alcohol usage is higher compared to the findings in a study done in the District of Gampaha, where only $37.7 \%$ of men in the general population had been regular drinkers (9) In this study the prevalence of smoking was $53.6 \%$ and $40.9 \%$ of them smoke on an average 6- 10 cigarettes per day. According to Williams (10) the total health of the driver is a confirmed protective factor in relation to the RTA prevention. Being a driver of a TW is more or less a sedentary occupation. Therefore, physical exercise is an essential component in maintaining both physical and mental wellbeing of the driver. In this study we found that only $36.4 \%$ of the drivers engaged in physical exercises, among them only $4 \%$ of them do physical exercises daily. The study found that $96.7 \%$ of drivers engaged in at least one spiritual activity daily. Although this is a favorable quantitative finding with among TW drivers, it needs to be emphasized using qualitative methods.

Study results revealed that $99.4 \%$ of the drivers in the study population possessed valid driving licences belonging to at least one class category. It is a favourable finding for road safety. However $0.6 \%$ without a valid driving licence is an extremely low percentage compared to the findings of Dharmarathne (6) in 2001 where $22.6 \%$ of drivers of TWs were without valid driving licences in the Kandy Police area. This difference may be due to, increase of fine for the traffic offence for driving without license and, increased traffic police surveillance activities. The fact that the whole study population being registered for passenger hiring purpose in UC area Panadura also may have contributed to the high percentage of TW drivers having driving licence. Lack of proper education and understanding of the driver's functioning in maneuvering the vehicle along the road, contributes in large measure to bad driver behavior. Therefore, adequate and quality training of a TW driver under the supervision of a qualified person is vital in order to achieve road safety (11). In this study a vast majority $(92.9 \%, \mathrm{n}=$ 314) of the drivers had learnt driving TWs by themselves Considerable percentage $(87.2 \%)$ of the drivers had taken less than 3 days to learn to drive the TW.

Furthermore, according to the chief examiner of the department of motor traffic, a trainee driver of a TW should undergo at least 20 hours practical training for at least two weeks under the supervision of a competent driver who holds a valid driving licence to drive TWs. In addition the trainee driver should gain knowledge, on road traffic rules, and regulations, traffic signals and sings and technical knowledge of vehicle during the training period (12). Therefore, it is obvious that the self training of less than 3 days to drive TWs is grossly inadequate. Occurrence of RTA in relation to the age of the driver shows a ' $U$ ' shape relationship, that is younger drivers and old drivers tend to meet with RTAs than middle aged drivers this phenomenon may be due to the effect of inexperience in the younger age group and effect of medical impairments in the older age group (13). According to the findings of this study there was no statistically significant difference in occurrence of RTA in relation to the age of the driver. 
This contradict finding could be due to the fact that most $(75.7 \%, \mathrm{n}=256)$ of the drivers in the study population belongs to 26-45 year age group.

Somasundaraswarans \& Toy (2005) had found statistically significant inverse association between the experience of the driver of TW and occurrence of RTA (8). In this study same association did not show statistical significance.

We found that RTA among the drivers who drive rented TWs are more than two times $(\mathrm{OR}=2.48 ; \mathrm{CI}=1.32$ - 4.66) higher than among those who drive their own TWs. This observed difference is statistically significant $(\mathrm{p}=0.004)$. Although not statistically significant, Somasundaraswarans \& Toy had also observed a low crash rates among driver owned TWs (8). This may be due to the differences on maintenance of the TW, safety measures and the care while driving.

In this study occurrence of RTA did not show significant association with working hours per day, although some studies had reported statistically significant high incidence of RTA among the drivers who work fewer hours per day (8). Therefore traditional approach of managing fatigue among the drivers in order to prevent RTAs, need to be revised with regard to the TW drivers in developing country like Sri Lanka. There are many scientific evidences to prove the fact that drinking and driving is a deadly mix. According to a study done by Gururaj, alcohol is a major risk factor for RTAs as it impairs judgment and increases the possibility of involvement in other high risk behaviours like speeding and violating traffic rules (14). Similarly this study too found that the occurrence of RTA is more than two fold $(\mathrm{OR}=2.06 ; \quad \mathrm{CI}=1.11-3.79)$ higher among the drivers who reported driving under the influence of alcohol compared to those who do not do so $(\mathrm{p}=0.02)$. The Driver Training Handbook for Sri Lanka (11) has described many distracters which affect the concentration and the efficiency of driving. Carrying on a conversation with the passenger, lighting a cigarette, adjusting the cassette player, using a mobile telephone, eating snacks are considered to be distracters to the driver. Peters \& Peters (14) had mentioned in their study that serious health problem were developing from automobile collisions caused by distracted drivers. This could be a result of the rapid proliferation of portable cellular telephones and personal organizers used while driving. Of the two distracters, we studied we found that smoking while driving can lead to more than twofold $(\mathrm{OR}=2.27 ; \mathrm{CI}=1.23$ - 4.19) higher incidence of RTA, and this association was statistically significant ( $\mathrm{p}$ $=0.007$ ). Where as Using mobile phones while driving did not show statistically significant association with occurrence of RTA

A limitation of the is study is that all the information was gathered from the TW drivers and the information on RTA could not be checked against any other source of data.

\section{Conclusion}

A substantial proportion of TW drivers use alcohol and smoke. Most of the drivers had inadequate and informal 
training to drive TWs. RTAs are more common among drivers who drive rented TWs, who have the habit of drink and drive and smoke while driving compared to drivers who drive their own TWs, who never drink and drive and who never smoke while driving. Therefore, it is recommended to conduct health promotion programme to reduce the prevalence of smoking and alcohol usage, to streamline the TW driver training and procedures of obtaining license, and to increase the surveillance activities on drink and driving.

\section{Acknowledgement}

We wish to thank Sri Lanka Medical Association, research fund for providing funds to carry out this study.

\section{References.}

1. Peden M, Scurfield R, Sleet D, Mohan D, Hyder AA, Jaravan E and Mathers C. World report on road traffic injury prevention. Geneva: World Health Organization; 2004

2. Sri Lanka traffic Police head quarters. Hand book on road traffic rules for schoolchildren : Colombo Sri Lanka traffic Police head quarters; 2008

3. Farlex free dictionary [online] ) [Accessed 2008September]. Available from (http://www.thefreedictionary.co m/three-wheeler

4. Department of Motor Traffic. Annual statistical report [ on CD ROM]
Department of Motor Traffic:

Colombo; 2007

5. Traffic Police headquarters, Statistics on road traffic accidents in Sri Lanka [On CD ROM]. Traffic Police head quarters: Colombo; 2007

6. Dharmarathne SD, Road traffic accidents in Kandy Police area and its economic impact. [ MDThesis].Post Graduate Institute of Medicine, University of Colombo; 2001

7. Henderson M, ed.. Public health and road safety: why can't we live without our roads? 1990. [online] [Accessed 2008 September].Available from: http://www.adf com.au/contentphp? subdir=library/1990/roadaccident/\&fi fename $=$ acid disease

8. Somasundaraswarann AK, Richard $\mathrm{T}$,. Self Reported Differences Between Crash-involved and NonCrash-Involved Three Wheeler Drivers in Sri Lanka; 2005. [online] [Accessed 2008 September]. Available from:http:// www.iatss.or.jp/pdf/research/30/301-07.pdf

9. Pathmeshwaran A,. Prevalence of and risk factors for hazardous drinkingamd alcohol use disorders among married men in Wattala Divisional Secretariet area. [ MDThesis]. Post Graduate Institute of Medicine, University of Colombo ; 1997 
10. Williams N, Traffic accidents epidemiology and medical aspects of prevention. Canadian medical association journal vol 90, 1964 [online] [Accessed 2008 December]. Available from:

http://www.pubmedcentral.nih.gov/pi crender.fegi?artid=1922713biobtype $=$ pdf

11. Ministry of transport and Swedish National Road Consulting AB. Driver Training hand book for Sri Lanka .Colombo: Ministry or transport ;2004

12. Premarathne S A, Chief motor traffic examiner, (personal communication)

Department of motor traffic Colombo; 2008

13. Dorn L, Af- Wåhlberg A,. Workrelated road safety: an analysis based on U.K. bus driver performance. Journal of safety research;40(3):197201, 2008 [online] [Accessed 2008 December].Available from: http://www.ncbi.nlm.nih.gov/sites/ent $\underline{\text { rez }}$

14. Gururaj G, Alcohol and road traffic injuries in South Asia: challenges for prevention. Journal of the college of physicians and surgeons in Pakistan 14(12) 2004. [online] [Accessed 2008 September].
Available from:

http://www.ncbi.nlm.nih.gov/pub med/15610627?ordinalpos=41\&i tool=EntrezSystem2.PEntrez.Pub med.Pubmed_ResultsPanel.Pub med_DefaultReportPanel.Pubme d RVDocSum

15.Peters G, Peters B J,. The distracted driver. Journal of the Royal Society of Health 121 (1.) 2001 [online] [Accessed 2008 September].Available from: http://www.ncbi.nlm.nih.gov/pubmed/11 329694? ordinalpos=35\&itool=EntrezSys tem2.PEntrez.Pubmed.Pubmed_ResultsP anel.Pubmed_DefaultReportPanel.Pubme d_RVDocSum 